\title{
Quality of specimens and sputum culture results: a retrospective study
}

\author{
M. RAHMAN \\ D.Bact., M.R.C.Path. \\ Department of Microbiology, King's Mill Hospital, Sutton-in-Ashfield, Nottinghamshire NG17 4JL
}

\begin{abstract}
Summary
A retrospective study of laboratory reports of sputums examined in the first 3 months of 1977 and of 1978 showed some interesting findings, which were similar in these 2 years. Analysis of the findings demonstrated that information from a proportion of sputum cultures were not helpful to the clinicians. Probable causes of such unhelpful results and some ways to overcome these problems were discussed, along with reviews of relevant literature. A conclusion drawn at the end of the discussion was that, under present circumstances, it was not expected that sputum cultures would produce totally reliable aetiological agents, unless attempts were made to obtain a better quality of specimen, e.g. those obtained by transtracheal or bronchoscopic aspirations.
\end{abstract}

\section{Introduction}

Sputum culture is one of the commonest investigations carried out in a microbiology laboratory, yet its reliability is often questioned by clinicians as well as microbiologists (Barrett-Connor, 1971; Lawson and MacDonald, 1977; Wilkinson et al., 1977). In response to certain physicians' requests for evaluation of culture results, methods, and quality of specimens received in the laboratory of the Department of Microbiology, King's Mill Hospital, Sutton-in-Ashfield, this study was undertaken.

\section{Materials and methods}

Procedures of sputum examination in the laboratory

All specimens were examined for condition of the containers and sputum. Specimens, appearing salivary or in leaking containers were discarded without any further examination. A smear was made from the most purulent part of each specimen for Gramstaining and the whole specimen was then homogenized by the method described by Rawlins (1953). Culture was made from each homogenized specimen on to blood-agar, chocolate-agar and MacConkey plates. A Gram-stained smear was examined for presence of leucocytes and organisms. When organisms were seen their morphological characters were also : noted (e.g. Gram-positive or negative, cocci or bacilli, etc.). Any growth of Streptococcus pneumoniae or Haemophilus influenzae wis always reported irrespective of its presence in pure or mixed growth or number. For other organisms, e.g. Staphylococcus pyogenes and Klebsiella spp., significance of the growths were always assessed with other factors which included Gram-stain findings, quantity and quality of growth and clinical information.

\section{Method of studying reports}

Back copies of reports of all sputum examinations made in the first 3 months of 1977 and 1978 were collected. The first 3 months were selected as this period was thought to have produced increased numbers of chest infections. Similar periods in 2 consecutive years were included for this study in order to see if the findings were likely to be reproducible. Requests for acid fast bacilli were excluded from this study. The number of total requests, unsuitable specimens, growths of normal flora and pathogens and Gram-stain findings were recorded.

\section{Analysis of results}

Unsuitable specimens

Twenty-eight out of 529 specimens received in the study period of 1977 were unsuitable for examinations $(5 \cdot 2 \%)$. For the same period in 1978 , unsuitable specimens were 27 out of 627 received $(4 \cdot 3 \%)$. Of all unsuitable specimens, the majority consisted of saliva $(78.5 \%$ in 1977 and $74 \%$ in 1978). Other examples of unsuitable specimens were leaking containers, insufficient specimens, specimens containing vomited materials, and empty containers.

\section{Direct microscopy}

Presence of leucocytes and their associations with the growths, in percentages, are shown in Table 1. It shows that about $66 \%$ of specimens growing normal flora only had leucocytes. Where some pathogens had grown; leucocytes were seen in $85-88 \%$ of specimens. From those growing pure growth of one pathogen only, leucocytes were seen in $93-97 \%$ of specimens. Organisms of one or more morphological types were seen in all specimens of 1977. Organisms of only one morphological type were seen in $76 \%$ of specimens producing pure growth of one pathogen; on the other hand; one type of organism 
was found in $32.5 \%$ of specimens producing mixed growth. Findings of organisms were missing in some of the 1978 reports and these figures were excluded from this study.

TABle 1. Percentages of specimens showing leucocytes in direct smear

\begin{tabular}{lll}
\hline Specimens & 1977 & 1978 \\
\hline $\begin{array}{l}\text { Growing normal flora only } \\
\text { Growing pathogens with or without }\end{array}$ & 68 & 66.6 \\
$\quad$ normal flora & 85.8 & 88.4 \\
Pure growth of one pathogen only & $93 \cdot 2$ & 97 \\
\hline
\end{tabular}

\section{Growth}

Two-hundred-and-fifty-eight specimens out of 529 examined in 1977 produced normal flora only. In the same period of 1978 , normal flora were grown in 300 out of 627 specimens examined. The percentages of normal flora and pathogens grown are shown in Table 2. Commonest pathogen isolated was $H$. influenzae in both years. Other common pathogens were Strep. pneumoniae, Staph. pyogenes and Klebsiella spp. Pure growths of 'one pathogen only' were found in less than $25 \%$ of all cultures showing pathogens. Some specimens grew 2 pathogens together; and in such cases $H$. influenzae and Strep. pneumoniae were the commonest pairs to be found (38\% of pairs of pathogens found in 1977 and $42 \%$ of those in 1978).

TABle 2. Normal flora and pathogens isolated in the study period (figures are in percentages)

\begin{tabular}{lll}
\hline & 1977 & 1978 \\
\hline Out of all specimens: & & \\
Growth of normal flora only & $48 \cdot 8$ & $47 \cdot 8$ \\
Growth of one or more pathogens & 46 & $47 \cdot 8$ \\
Out of all pathogens: & & \\
Pure growth of one pathogen & $24 \cdot 5$ & $21 \cdot 6$ \\
Two pathogens only & 12 & $17 \cdot 3$ \\
Haemophilus influenzae & 32.9 & 38.6 \\
Streptococcus pneumoniae & 13.9 & 16.6 \\
Staphylococcus pyogenes & 10.9 & 13.6 \\
Klebsiella spp. & $14 \cdot 3$ & 13.6 \\
\hline
\end{tabular}

\section{Discussion}

Figures stated in the preceding paragraphs and those in the Tables 1 and 2 show good similarity of all findings between the study periods of 1977 and 1978. This suggests that these observations are likely to be reproduced in any year under the same systems of sputum collection and laboratory procedures. It could be seen that a small proportion of specimens received were unsuitable for examination $(4 \cdot 3-5 \cdot 2 \%)$. But when one considered actual numbers these would not appear to be negligible (28 in the first 3 months of 1977 and 27 in the same period of 1978). Proportion of unsuitable specimens could even be higher in some other laboratories. For example, $17 \%$ of specimens received in one laboratory were saliva (Tebbutt and Coleman, 1978). All of these could have contributed to misdiagnosis or delayed diagnosis.

Two-thirds of specimens showing normal flora only had leucocytes in them. This could mean any of the following possibilities:

(a) A true pathogen could not be isolated or identified owing to the heavy overgrowth of contaminating mouth organisms; (b) the pathogen did not grow because of the prior use of antibiotics; (c) a non-bacterial pathogen was causing chest infection; and (d) presence of leucocytes in small numbers could not always indicate chest infection. Overgrowth of mouth organisms is a well known problem and may be overcome by culturing diluted liquefied specimens (Dixon and Miller, 1965) or culturing on selective media (Wilkinson et al., 1977). Previous use of antibiotics eliminates sensitive pathogens and allows growth of more resistant organismso which are not true pathogens (Wilkinson et al. $\overline{0}$ 1977). There is no way to overcome this in the $\mathbb{D}$ laboratory to get the pathogen from culture. Possi $\frac{\vec{\Phi}}{\overrightarrow{0}} \frac{\vec{D}}{\mathbb{D}}$ bility of a non-bacterial pathogen causing the in $\overline{3}$ fection would remain speculative until special cultures or serological tests establish existence of such an agent (Stokes, 1975). The association between pre sence of leucocytes in sputum and existence of ins fection has been more closely examined by Van Scoy (1977). He demonstrated that sputums containing more than 25 leucocytes per field of $\times 100$ magnification were more likely to be associated with chest infection and less likely to grow normal flora. He argued that sputums showing less than this number of leucocytes should not be cultured, except under special circumstances or on specific request from clinicians. Similar observations were also made by Tebbutt and Coleman (1978). Detecting organisms from direct microscopy was not found to be of much use in the present study, as $24 \%$ of specimens producing pure growth of one organism only showed more than one organisms in the direct smear; on the other hand, $32.5 \%$ of specimens growing mixed growth showed only one organism in the direct smear. To obtain a reliable information from the direct Gram-stained smear, one has to obtain a specimen by bronchoscopic or transtracheal aspiration which are known to be free from false positive or false negative results (Thorsteinsson, Musher and Fagan, 1975).

Less than $50 \%$ of specimens grew known pathogens. Equal numbers of specimens grew normal flora. Of all specimens growing any pathogen, pure 
growths (i.e. one organism only from one specimen) were found in less than $25 \%$ of cases. This fact and the absence of leucocytes in $12-14 \%$ of specimens producing certain pathogens, indicate that in at least a proportion of cases these known pathogens were part of normal flora in the mouth and throat and did not produce chest infection. Under the present system of reporting, it could not be possible to confirm that an isolated pathogen was producing the chest infection. Some form of quantitative or semi-quantitative reporting system might be helpful. Thorsteinsson et al. (1975) have found that causative pathogens in chest infections were present in a number $\geqslant 10^{7} / \mathrm{ml}$ of sputum; whereas other contaminating organisms never exceeded $10^{5} / \mathrm{ml}$. However, counting organisms from sputum is a research work and unlikely to find a place in routine laboratories. Culturing diluted specimens (Dixon and Miller, 1965) would be a reasonable compromise. Most reliable information would be obtained from transtracheal or bronchoscopic aspirations. But it is unlikely to be acceptable to many physicians in hospitals or any in general practice.

It could thus be concluded in the words of Van Scoy (1977) that, under the present circumstances, routine sputum culture was 'expected to serve the clinician more as a clue' and could not be expected to be 'totally reliable in demonstrating the aetiologic agent'. Improvements could be made by (a) selecting suitable specimens on the basis of naked eye appearance and microscopic finding of certain minimum number of leucocytes, (b) culturing homogenized and diluted specimens, (c) using selective media and (d) preventing the prior use of antibiotics. Most reliable information, however, could only be expected from specimens obtained by bronchoscopic or transtracheal aspiration.

\section{References}

BARRETT-CONNOR, E. (1971) The non-value of sputum culture in the diagnosis of pneumococcal pneumonia. American Review of Respiratory Disease, 103, 845.

Dixon, J.S.M. \& Miller, D.C. (1965) Value of dilute inocula in cultural examination of sputum. Lancet, ii, 1046.

LAwson, D.H. \& MacDonald, S. (1977) Antibacterial therapy in general medical wards. Postgraduate Medical Journal, 53, 306.

RAWLiNS, G.A. (1953) Liquefaction of sputum for bacteriological examination. Lancet, ii, 538.

Stokes, E.J. (1975) Clinical Bacteriology. Fourth edn, pp 86-90. Edward Arnold (Publishers) Ltd, London.

Tebbutt, G.M. \& Coleman, D.J. (1978) Evaluation of some methods for the laboratory examination of sputum. Journal of Clinical Pathology, 31, 724.

Thorsteinsson, S.B., Musher, D.M. \& Fagan, T. (1975) The diagnostic value of sputum culture in acute pneumonia. Journal of the American Medical Association, 233, 894.

VAN Scoy, R.E. (1977) Bacterial sputum cultures-a clinician's viewpoint. Proceedings. Mayo Clinic, 52, 39.

Wilkinson, P.J., Ball, A.J., Doran, J., Gillespie, W.A. \& OrTON, V.S. (1977) Routine laboratory assessment of postoperative chest infection: a prospective study. Journal of Clinical Pathology, 30, 417. 